\title{
CO-IMMOBILIZATION OF SEMAPHORIN3A AND NERVE GROWTH FACTOR TO GUIDE AND PATTERN AXONS
}

\author{
Aleesha M. McCormick, Natalie A. Jarmusik, Nic D. Leipzig* \\ Department of Chemical and Biomolecular Engineering \\ The University of Akron
}

For submission to:

Acta Biomaterialia

*Corresponding Author:

Nic D. Leipzig

nl21@uakron.edu

200 East Buchtel Common

Whitby Hall 211

Akron, OH 44325-3906

USA

Telephone: $330-972-6881$

Fax: 330-972-5856 


\begin{abstract}
Immobilization of axon guidance cues offers a powerful tissue regenerative strategy to control the presentation and spatial location of these biomolecules. We use our previously developed immobilization strategy to specifically tether recombinant biotinylated nerve growth factor (bNGF) and biotinylated semaphorin3A (bSema3A) to chitosan films as an outgrowth and guidance platform. DRG neurite length and number for a range of single cues of immobilized bNGF or bSema3A were examined to determine a concentration response. Next single and dual cues of bNGF and bSema3A were immobilized and DRG guidance was assessed in response to a step concentration change from zero. Overall, immobilized groups caused axon extension, retraction and turning depending on the ratio of bNGF and bSema3A immobilized in the encountered region. This response indicated the exquisite sensitivity of DRG axons to both attractive and repulsive tethered cues. bSema3A concentrations of 0.10 and $0.49 \mathrm{ng} / \mathrm{mm}^{2}$, when co-immobilized with bNGF (at 0.86 and $0.43 \mathrm{ng} / \mathrm{mm}^{2}$ respectively), caused axons to turn away from the co-immobilized region. Immunocytochemical analysis showed that at these bSema3A concentrations, axons inside the co-immobilized region display microtubule degradation and breakdown of actin filaments. At the lowest bSema3A concentration $\left(0.01 \mathrm{ng} / \mathrm{mm}^{2}\right)$ coimmobilized with a higher bNGF concentration $\left(2.16 \mathrm{ng} / \mathrm{mm}^{2}\right)$, neurite lengths are shorter in the immobilized area, but bNGF dominates the guidance mechanism as neurites are directed toward the immobilized region. Future applications can pattern these cues in various geometries and gradients in order to better modulate axon guidance in terms of polarity, extension and branching.
\end{abstract}

Key words: nerve growth factor, semaphorin3A, dual immobilization, axon guidance, radial plots, circular statistics, nerve regeneration 


\section{Introduction}

Axon pathfinding is a vital neuronal process for proper formation and patterning of the nervous system as well as innervation and recovery after nervous system injury. Thus, anatomical development and regeneration is heavily dependent on localized expression of guidance molecules in order to facilitate axon guidance mechanisms. The growth cone, the leading edge of the axon, will detect permissive and inhibitory signals from soluble and substrate-bound molecules in the extracellular environment and subsequently direct the axon along its intended path. Once bound to growth cone surface receptors, guidance signals are then transduced by cytoplasmic signaling pathways that promote cytoskeletal rearrangement and directed motility and growth [1]. These biomolecules, present in the surrounding microenvironment, often work in concert with each other to achieve directional efficiency of neuronal guidance to the appropriate targets (for reviews see [2, 3]).

Two families of neuronal proteins especially proficient in chemotaxis and haptotaxis include the semaphorins and the neurotrophins. Semaphorins are considered mainly a repulsive cue since, once bound with a semaphorin receptor neuropilin, they can induce a collapse in the growth cone and thereby effectively prevent any opportunity for further neurite growth [4]. In contrast, the neurotrophin nerve growth factor (NGF) is considered a chemoattractant because of its ability to initiate neurites while enhancing extension after protein-cell receptor interaction. The cell receptors that activate this process are p75 neurotrophin receptor (p75NTR) and tropomyosin receptor kinase A (TrkA) receptor [5, 6]. A suggested synergism between attractive and inhibitory cytokines indicates the possibility to exhibit greater control on axon guidance and proper patterning [7], which is vital to tissue repair after nervous system injury. This is evident with netrins (permissive) and slits (inhibitory) that are responsible for the patterning and 
development of spinal cord tracts [8,9]. Many other guidance proteins (such as chondroitin sulfate proteoglycans (CSPGs), ephrins, netrin-1, semaphorin3D) direct retinal ganglion axons from the eye to the brain (for review see [10]). Additionally, NGF and semaphorin3A (Sema3A) play a major role in regulating sensory neuron extension and pathfinding [11-13]. Therefore, this endogenous distribution of permissive and inhibitory guidance factors, specifically NGF and Sema3A, motivated us to examine the dual effects these biomolecules implement on sensory neuron guidance.

In the living environment haptotaxis plays a significant role in many cellular functions, ranging from morphogenesis and embryonic development to regenerative processes [14]. Immobilization of biomolecules has been used as a strategy to decrease dosing requirements for tissue-regeneration by increasing sustainability of the molecule as well as better modulation of orientation and spatial location of these factors (for review see [15]). Additionally, immobilization of factors is found endogenously largely through protein sequestration by extracellular matrix molecules, which serves to enhance biomolecular responses as well as cell recruitment to areas of trauma $[16,17]$. The strong interactions associated with immobilization of growth factors and proteins have elicited significantly better and appropriate cellular responses compared to adsorbing the protein to a biomaterial substrate $[18,19]$. Based on this evidence, immobilizing guidance molecules will be our strategy in modulating axon outgrowth and guidance.

For this study, we use a previously reported immobilization method using a heterobifunctional crosslinker, a maleimide-streptavidin molecule and recombinant biotinylated proteins, NGF and Sema3A [19]. Building upon these findings, the focus and novelty of this study is to examine axon guidance responses to co-immobilized uniform concentrations of NGF 
and Sema3A. This is accomplished by (1) determining concentration effects within the region to either immobilized NGF or Sema3A through neurite outgrowth and number assessment and (2) analyzing axon guidance (neurite outgrowth/inhibition and turning) when DRGs are cultured outside of and near regions containing both immobilized NGF and Sema3A. From this study, we

discover how DRGs respond to ever-present and encountered co-immobilized cues of NGF and Sema3A. We compare these findings to previous experiments utilizing both soluble and immobilized NGF and Sema3A as outgrowth and guidance methods. Additionally, these findings expand our immobilization strategies to modify and propel our guidance model into future regenerative applications.

\section{Material and Methods}

\subsection{Synthesis of Heterobifunctional Crosslinker and Guidance Proteins}

N-(2-mercaptoethyl)-3-(3-methyl-3H-diazirine-3-yl) propanamide (N-MCEP-diazirine) was synthesized in the dark as we have reported previously [19]. Briefly, 4-oxopentanoic acid (Sigma, St. Louis, MO, USA) and cysteamine (Sigma) were refluxed overnight at $120^{\circ} \mathrm{C}$. The product was purified by flash chromatography and freeze-dried. For the addition of the diazirine component, the procedure was completed in the dark because low wavelengths can degrade intermediates and the final product. First, the freeze-dried product was refluxed with $3 \%$ ammonia solution (J.T. Baker, Phillipsburg, NJ, USA) at $4^{\circ} \mathrm{C}$ for $5 \mathrm{~h}$. The reaction was reduced to $-78^{\circ} \mathrm{C}$ and hydroxylamine-O-sulphonic acid solution (Sigma) was gradually added and stirred for an additional $5 \mathrm{~h}$. The reaction continued overnight to allow excess ammonia to evaporate. This solution was then washed with $\mathrm{CH}_{3} \mathrm{OH}$ (Mallinckrodt Baker Inc., Phillipsburg, NJ, USA) and triethylamine (Sigma) was added. The mixture was cooled to $0^{\circ} \mathrm{C}$, titrated with $\mathrm{I}_{2}$ solution (Sigma) and purified again by flash chromatography. 


\subsection{Immobilization of bNGF and bSema3A}

bNGF (29 kDa) and bSema3A (91 kDa) were synthesized as we have reported previously $[19,20]$. To immobilize these proteins, chitosan films were prepared [19]. Briefly, chitosan (Novamatrix, Sandvika, Norway) was dissolved at $2 \mathrm{wt} \%$ in acetic acid and $3 \mathrm{~mL} /$ well was pipeted into a 6 well-plate, for co-immobilization guidance studies, or $0.5 \mathrm{~mL} / \mathrm{well}$ in a 48 -well plate for protein concentration analysis. The plates were dried in a fumehood for $24 \mathrm{~h}$, neutralized with an ammonium hydroxide solution $\left(\mathrm{NH}_{4} \mathrm{OH}: \mathrm{ddH}_{2} \mathrm{O}: \mathrm{CH}_{3} \mathrm{OH}\right.$ at 3:7:90) and washed in phosphate buffered saline (PBS, $\mathrm{pH}=7.4$ ). First, the diazirine ring on the N-MCEPdiazirine was attached to the primary amines of the chitosan film at $25 \mathrm{mM}$ when exposed to UV light $\left(365 \mathrm{~nm}, 8 \mathrm{~W}, 2.7 \mathrm{~mW} / \mathrm{cm}^{2}\right)$ for $10 \mathrm{~min}$. Films were then washed in PBS $(\mathrm{pH}=7.4)$ with 50 $\mathrm{mM}$ dithiothreitol (DTT, Chem-Impex International) and rinsed with PBS (pH = 7.4). Next, maleimide-streptavidin (mal-strep, $0.2 \mu \mathrm{M}$, Sigma) was attached to the crosslinker for at least $2 \mathrm{~h}$ at room temperature in PBS containing $20 \mathrm{mM}$ Tris (2-carboxyethyl) phosphine hydrochloride (TCEP, $\mathrm{pH}=7.4$, Chem-Impex International). After washing films in PBS again, the biotinylated proteins were added at their respective concentrations for each experiment below overnight at $4^{\circ} \mathrm{C}$. Using a 16- or 18- gauge needle and syringe, films were extensively washed in $20 \mathrm{mM}$ Tris-hydrochloride $+150 \mathrm{mM} \mathrm{NaCl}+0.1 \%$ Tween $20($ TBST, $\mathrm{pH}=7.5)$, the plates were

rocked for $1 \mathrm{~h}$, and then the process was repeated two more times. Films were finally rinsed in PBS $(\mathrm{pH}=7.4)$.

\subsection{Concentration Response of bNGF and bSema3A on DRG Outgrowth}

For cell studies, films were sterilized in $70 \%$ ethanol for 30 min. Laminin (Life Technologies, Grand Island, NY, USA) was adsorbed to the films for at least $3 \mathrm{~h}$ at room temperature at a final concentration of $5 \mu \mathrm{g} / \mathrm{mL}$ before the proteins were immobilized. The same 
protein immobilization procedures were performed under aseptic conditions for DRG outgrowth studies.

DRG extracts were obtained from $9 \mathrm{~d}$ chick embryos, cleaned of any debris, and set into wells containing serum free medium (13.4 g/L DMEM (Dulbecco's Modified Eagles Medium), $1.176 \mathrm{~g} / \mathrm{L}$ sodium bicarbonate, $1 \% \mathrm{~L}$-glutamine (Life Technologies), $1 \%$ streptomycin-penicillin (Life Technologies), $5 \mu \mathrm{g} / \mathrm{mL}$ human insulin, $5 \mu \mathrm{g} / \mathrm{mL}$ transferrin, $3 \times 10^{-8} \mathrm{M}$ sodium selenite, $100 \mu \mathrm{M}$ putrescine, $2 \times 10^{-8} \mathrm{M}$ progesterone, all Sigma) [19]. These culture parameters containing non-serum medium has shown to reduce non-neuronal populations after DRG isolation [21]. The addition of NGF enhances DRG survival compared to the medium alone and has been used as a standard for outgrowth and guidance studies, with $10-20 \mathrm{ng} / \mathrm{mL}$ being the optimal concentration range for embryonic day 15 DRG neurons [22]. Therefore, soluble NGF will be added as a positive control parameter for these studies. DRG were placed in 48-wellplates containing applied concentrations of either $0,500,1000,2500,5000$ or $10,000 \mathrm{ng} / \mathrm{mL}$ bNGF concentrations and a separate group containing $10 \mathrm{ng} / \mathrm{mL}$ soluble mouse NGF (Sigma) or applied concentrations of $0,100,250,1000$, or $5000 \mathrm{pM}(9.1,23,91,457 \mathrm{ng} / \mathrm{mL}) \mathrm{bSema} 3 \mathrm{~A}$. For bSema3A experiments, $10 \mathrm{ng} / \mathrm{mL}$ soluble NGF was added to the well-plates for $24 \mathrm{~h}$ to aid in initial DRG outgrowth. After $24 \mathrm{~h}$, fresh medium was added containing no NGF for the remainder of the $5 \mathrm{~d}$ study.

Brightfield images were obtained after 5 days to quantitate neurite outgrowth and number. Images were taken at $4 \mathrm{X}$ magnification in order to obtain a clear view of the DRG extract and associated neurites which aided in the ease and accuracy of axon measurements. A line segment tool in ImageJ was used to measure the length of the axon from the DRG extract to the tip of the neurite, and the software recorded neurite number as well. DRGs that had minimal to no non- 
neuronal cell types were quantified in order to reduce variability to DRG cell outgrowth. bNGF concentration studies consisted of a sample size of 3 to 4 DRG per group, and bSema3A had 8 to 10 DRG analyzed per group.

Protein concentration and immobilization efficiency was determined for both bNGF and bSema3A. A NanoOrange protein quantification kit (Life Technologies) was utilized to determine the percent of protein immobilized to a chitosan film compared to its soluble counterpart in solution. Immobilized films were produced in triplicate and prepared in the same manner as the films for the DRG concentration experiment except laminin was not adsorbed to these films so that it did not interfere with the assay quantification.

\subsection{Co-immobilization Study with bNGF and bSema3A}

Films were sterilized and laminin adsorbed for DRG guidance studies in 6-well-plates. A silicone isolator (13 mm, JTR13R-2.0-Press-To-Seal Silicone Isolator, Grace Bio-Laboratories, Bend, OR, USA) was sealed inside the 6-well-plates. This region was where the protein immobilization took place (Fig. 1). bNGF and bSema3A were solely attached in the region of the isolator at $1000 \mathrm{ng} / \mathrm{mL}$ and $1000 \mathrm{pM}$, respectively. Combinations of bNGF and bSema3A were attached together as follows: $500 \mathrm{ng} / \mathrm{mL}$ bNGF + $5000 \mathrm{pM} \mathrm{bSema3A,} 1000 \mathrm{ng} / \mathrm{mL} \mathrm{bNGF}+$ $1000 \mathrm{pM}$ bSema3A and $2500 \mathrm{ng} / \mathrm{mL} \mathrm{bNGF}+100 \mathrm{pM}$ bSema3A. DRG extracts were placed around the immobilized regions and brightfield images were acquired at $4 \mathrm{X}$ magnification at day 5 in order to quantitate neurite length, number and orientation using ImageJ Software. Again, only DRG extracts with minimal to no other non-neuronal cell types were considered for measurements. All angle measurements for axons were adjusted to reflect the direction into the immobilized region to be from 0 to $<180^{\circ}$ and away from the region to be 180 to $<360^{\circ}$. For 
axon length and number, the entire DRG extract was measured in a $360^{\circ}$ manner and 800 to 1000 neurites were measured for each group.

Regarding neurite orientation, the direction of the tip of the axon and growth cone (last $50 \mu \mathrm{m})$ was measured to determine the angle or direction of turning. It is important to note that only axons within the immobilized region were measured, and 250 to 350 axons were measured for each group. The guidance of neurites was grouped into three directions (Fig. 1). As such, the percent distribution of axons directed into the immobilized source, 60 to $<120^{\circ}$, represents the tip of the axon pointing directly toward the source. Outside this range from either 0 to $<60^{\circ}$ or 120 to $<180^{\circ}$ is denoted as the turning region. Note that turning can mean that the growth cone is turning away from the source or toward the source. Finally, 180 to $<360^{\circ}$ represented neurites in the immobilized region that were going away from the immobilized protein source.

For immunocytochemical (ICC) analysis, DRG extracts were fixed in $3.7 \%$ paraformaldehyde at day 5 and permeabilized with 0.1\% Triton X-100 (Sigma). Samples were blocked with $10 \%$ fetal bovine serum (Life Technologies) in PBS for $1 \mathrm{~h}$ at room temperature. Monoclonal mouse anti- $\beta$-III tubulin (1:1000, Covance, Princeton, NJ, USA) was added as the primary antibody overnight at $4^{\circ} \mathrm{C}$, and the following day the secondary goat anti-mouse $\operatorname{IgG}$ AlexaFluor 546 (1:400, Life Technologies) was incubated on the samples for at least $2 \mathrm{~h}$ at room temperature. AlexaFluor 488 phallodin (1:200, Life Technologies) was added to the samples for an additional $2 \mathrm{~h}$ at room temperature, and images of DRG extracts were obtained using a fluorescent microscope (Olympus IX81, Tokyo, Japan).

\subsection{Statistical Analysis}

For concentration experiments, a one-way ANOVA using JMP 10.0 (SAS Institute, Cary, NC, USA) analyzed significance with HSD Tukey post hoc test. To represent axon guidance data 
optimally, circular statistical analysis followed a recent report [23]. For co-immobilization experiments the circular statistics program Oriana 4 (Kovach Computing Services, Pentraeth, Anglesey, Wales) evaluated uniformity of neurite length, number and orientation. Neurites were represented as a frequency plot placed in $20^{\circ}$ bins and wrapped around from $0-360^{\circ}$. A onesample Watson's $\mathrm{U}^{2}$ test was used for basic statistical analysis of uniformity for each group. Watson's $\mathrm{U}^{2}$ test also evaluated differences in distribution between groups in a pairwise fashion. These data are reported as mean \pm standard deviation (SD). Significance was established with an $\alpha$ level of 0.05 .

\section{Results}

\subsection{DRG Outgrowth Response within Increasing Single Concentrations of Immobilized bNGF} and $b \operatorname{Sema} 3 A$

The binding efficiency for bNGF and bSema3A was $38 \pm 12 \%$ and $55 \pm 7 \%$, respectively, as determined by the NanoOrange protein kit. However, these calculations were extrapolated from the efficiency at one applied concentration, $1000 \mathrm{ng} / \mathrm{mL}(38 \pm 12 \%)$ and 1000 pM $(55 \pm 7 \%)$ for bNGF and bSema3A, respectively. We made the assumption that this efficiency would be the same at the other applied concentrations for bNGF and bSema3A as similar maleimide-streptavidin immobilization strategies have shown about $50 \%$ attachment for neuronal differentiation proteins [24]. Additionally, laminin was not present during this assay, and the protein binding kinetics could possibly differ slightly as a result of laminin present in our cell studies, altering the surface area values for these immobilized proteins. Based on the

calculated efficiency for bNGF, the applied concentrations of 500, 1000, 2500, 5000 and 10,000 $\mathrm{ng} / \mathrm{mL}$ resulted in immobilized concentrations of $190,380,950,1900$ and $3800 \mathrm{ng} / \mathrm{mL}$, respectively. For bSema3A, the applied concentrations of 100, 250, 1000 and 5000 pM resulted 
in $47,117.5,470$ and $2350 \mathrm{pM}(4.3,11,43$ and $215 \mathrm{ng} / \mathrm{mL})$ based on the binding efficiency. Table 1 summarizes these results and includes the surface area concentration for each DRG outgrowth and guidance experiment. From this point forward the concentrations for simplicity sake will be designated as the following for bNGF: $0.5,1,2.5,5$ and $10 \mathrm{X}$ (based on the 1000 $\mathrm{ng} / \mathrm{mL}$ applied concentration); and for bSema3A: $0.1,0.25,1$ and $5 \mathrm{X}$ (based on the $1000 \mathrm{pM}$ applied concentration). Control groups are noted as having $0 \mathrm{X}$ concentration.

Table 1. Applied and Actual Concentrations of Immobilized bNGF and bSema3A

\begin{tabular}{|c|cccccc|}
\hline $\begin{array}{c}\text { Immobilized } \\
\text { Protein }\end{array}$ & $\begin{array}{c}\text { Applied } \\
(\mathbf{p M})\end{array}$ & $\begin{array}{c}\text { Applied } \\
(\mathbf{n g} / \mathbf{m L})\end{array}$ & $\begin{array}{c}\text { Based on } \\
\text { Binding } \\
\text { Efficiency } \\
(\mathbf{n g} / \mathbf{m L})\end{array}$ & $\begin{array}{c}\text { 48-well } \\
\text { Plate } \\
\text { Surface } \\
\text { Area } \\
\left(\mathbf{n g} / \mathbf{m m}^{2}\right)\end{array}$ & $\begin{array}{c}\text { Silicone } \\
\text { Isolator } \\
\text { Surface } \\
\text { Area } \\
\left(\mathbf{n g} / \mathbf{m m}^{2}\right)\end{array}$ & $\begin{array}{c}\text { Designated } \\
\text { Concentration }\end{array}$ \\
\hline \multirow{5}{*}{ bNGF } & - & 500 & 190 & 0.58 & 0.43 & $0.5 \mathrm{X}$ \\
& - & 1000 & 380 & 1.16 & 0.86 & $1 \mathrm{X}$ \\
& - & 2500 & 950 & 2.89 & 2.16 & $2.5 \mathrm{X}$ \\
& - & 5000 & 1900 & 5.79 & 4.32 & $5 \mathrm{X}$ \\
\hline \multirow{3}{*}{ bSema3A } & - & 1000 & 3800 & 11.6 & 8.6 & $10 \mathrm{X}$ \\
& 100 & 9.1 & 4.3 & 0.01 & 0.01 & $0.1 \mathrm{X}$ \\
& 250 & 23 & 11 & 0.03 & 0.02 & $0.25 \mathrm{X}$ \\
& 1000 & 91 & 43 & 0.13 & 0.10 & $1 \mathrm{X}$ \\
\hline
\end{tabular}

Neurite length and number were quantified first at increasing single concentrations of immobilized bNGF and bSema3A to understand concertation responses before moving to guidance studies (Fig. 2). At day 5, neurite length showed significant differences with the soluble NGF group having the longest lengths of $1534 \pm 108.5 \mu \mathrm{m}(\mathrm{p}=0.0004$, Fig. 2A). The soluble NGF group was not significantly different from immobilized bNGF at $1 \mathrm{X}(1050 \pm 254.1 \mu \mathrm{m})$, but resulted in significantly longer neurites compared to all other concentrations. This result is evident where representative phase contrast images show increased neurite length for the soluble NGF group (Supp. Fig. 1). The number of neurites was also highly significant (Fig. 2B) with the 
soluble NGF group having a significantly larger number of neurites $(\mathrm{p}<0.0001,177 \pm 18)$ compared to all the groups except $2.5 \mathrm{X}$ bNGF $(130 \pm 38)$. The $1 \mathrm{X}$ bNGF group $(97 \pm 6)$ had significantly fewer neurites compared to the soluble NGF but had significantly more than $0 \mathrm{X}$ bNGF $(\mathrm{p}<0.0001,44 \pm 18)$.

For bSema3A immobilization (Fig. 2C), every concentration resulted in statistically significant shorter lengths $(\mathrm{p}<0.001 ; 0.1 \mathrm{X}$ at $696 \pm 259.7 \mu \mathrm{m}, 0.25 \mathrm{X}$ at $728 \pm 212.1 \mu \mathrm{m}, 1 \mathrm{X}$ at $710 \pm 347.5 \mu \mathrm{m}$ and $5 \mathrm{X}$ at $792 \pm 281.1 \mu \mathrm{m})$ compared to the control with $0 \mathrm{X}$ bSema3A $(1987 \pm$ 1137.7 $\mu \mathrm{m}$ ). The control group for bSema3A showed the longest DRG neurites (Fig. 3A) in phase contrast images as compared to DRG exposed to increasing immobilized bSema3A concentrations (Fig. 3B-E). The breakdown of the neurites caused by bSema3A is also shown (Fig. 3F). The number of neurites was also statistically significantly different (Fig. 2D) with $1 \mathrm{X}$ bSema3A having $18 \pm 10$ neurites compared to $0 \mathrm{X}$ bSema3A with $38 \pm 13$ neurites $(\mathrm{p}=0.0416)$.

\subsection{Length, Number and Distribution of Neurites Encountering Co-immobilized Protein Step}

\section{Concentration Change Regions}

For the length and number of neurites measured from $0-360^{\circ}$ there was nonuniform distribution for all groups except the control and $1 \mathrm{X}$ bNGF $+1 \mathrm{X}$ bSema3A (Fig. 4). Thus, neurites of all other groups were more concentrated and biased in a specific direction depending on the immobilized cue. For the $1 \mathrm{X}$ bNGF group Watson's $\mathrm{U}^{2}$ test showed a significantly biased distribution $(\mathrm{p}<0.005)$, and the mean vector $(\mu)$ for neurites extended directly into the immobilized region $\left(0\right.$ to $\left.<180^{\circ}\right)$ at $95^{\circ}$. $1 \mathrm{X}$ bSema3A neurites were also significantly concentrated $(\mathrm{p}<0.005)$ just outside the immobilized region at $199^{\circ}$. For the co-immobilized group $0.5 \mathrm{X}$ bNGF $+5 \mathrm{X}$ bSema3A was significantly biased $(\mathrm{p}<0.05)$ and, neurites were directed away from the immobilized region at $266^{\circ}$. For $2.5 \mathrm{X} \mathrm{NGF}+0.1 \mathrm{X}$ Sema3A a 
significant bias was also observed $(\mathrm{p}<0.025)$ with a mean direction of $141^{\circ}$ for the neurites, representing an orientation which is into the co-immobilized region. Furthermore, group-togroup comparisons revealed that $1 \mathrm{X}$ bNGF group distribution (Fig. 4B) and $1 \mathrm{X}$ bSema3A group distribution (Fig. 4C) were statistically significantly different from all the other groups (p $<0.001$ and $\mathrm{p}<0.02$, respectively). The neurite distribution of $0.5 \mathrm{X}$ bNGF $+5 \mathrm{X}$ bSema3A (Fig. 4D) was statistically significantly different (from $2.5 \mathrm{X}$ bNGF $+0.1 \mathrm{X}$ bSema3A $(\mathrm{p}<$ 0.005, Fig. 4F).

Neurite length was binned into various ranges and further analyzed by the percent distribution of neurite lengths into and outside the immobilized protein (both single and in combination) region (Supp. Fig. 2). The majority of neurites ranged from $>500-1000 \mu \mathrm{m}$ and $>$ $1000-1500 \mu \mathrm{m}$ for $1 \mathrm{X}$ bNGF were directed into the immobilized region, $68 \%$ and $65 \%$, respectively (Supp. Fig. 2B). For $1 \mathrm{X}$ bSema3A only $22 \%$ of neurites with length of $>1000-1500$ $\mu \mathrm{m}$ extended into the immobilized area (Supp. Fig. 2C). When these proteins were immobilized together, neurite length displayed a similar response to the control for the $0.5 \mathrm{X}$ bNGF $+5 \mathrm{X}$ bSema3A group (53\% for lengths $>500-1000 \mu \mathrm{m}$ and 57\% for lengths $>1000-1500 \mu \mathrm{m}$; Supp. Fig. 2D). Even though there was an even distribution of neurites for the $1 \mathrm{X} b \mathrm{bGF}+1 \mathrm{X}$ bSema3A group, longer neurites extended into the co-immobilized region (63\% for lengths > 1000-1500 $\mu \mathrm{m}$ and $86 \%$ for lengths $>1500-2000 \mu \mathrm{m}$; Supp. Fig. 2E). For higher concentrations of bNGF, only $35 \%$ of longer neurites > 1000-1500 $\mu \mathrm{m}$ extended into the co-immobilized region, but $61 \%$ of shorter neurites $0-500 \mu \mathrm{m}$ extended into the co-immobilized region (Supp. Fig. 2F). 


\subsection{Neurite Orientation within the Co-immobilized Protein Step Concentration Change Regions}

The directional preference of neurites that had already entered the immobilized protein regions were measured. All groups except the control (Fig. 5A) showed nonuniform distribution $(\mathrm{p}<0.005)$ regarding neurite orientation (the measured direction of the growth cone). The overall mean direction for $1 \mathrm{X}$ bNGF (Fig. 5B) group was $86^{\circ}$. The $1 \mathrm{X}$ bSema3A group (Fig. 5C) was directed at $50^{\circ}$, and similarly $0.5 \mathrm{X}$ bNGF $+5 \mathrm{X}$ bSema3A (Fig. 5D) showed concentration of neurites at $48^{\circ}$. Increasing the bNGF concentration caused neurite orientation to be more directed into the immobilized regions, $66^{\circ}$ for the $1 \mathrm{X}$ bNGF $+1 \mathrm{X}$ bSema3A group (Fig. 5E) and $73^{\circ}$ for $2.5 \mathrm{X}$ bNGF $+0.1 \mathrm{X}$ bSema3A (Fig. 5F). When evaluating pairwise comparisons via the Watson $\mathrm{U}^{2}$ test for each group, the control group was statistically significantly different from all other groups $(\mathrm{p}<0.001)$. The $1 \mathrm{X}$ bNGF distribution was statistically significantly different from all the immobilized groups except $2.5 \mathrm{X}$ bNGF $+0.1 \mathrm{X}$ bSema3A ( $\mathrm{p}<0.001$ ), and $1 \mathrm{X}$ bSema3A was statistically significantly different from all groups except $1 \mathrm{X} \mathrm{bNGF}+1 \mathrm{X}$ bSema3A and $0.5 \mathrm{X}$ bNGF $+5 \mathrm{X}$ bSema3A $(\mathrm{p}<0.001)$.

Furthermore, the guidance of neurites were broken into three directions for each group (Table 2) as described in Figure 1. The normal distribution of these regions is as follows: (1) "turning" regions consist of $33 \%$ of the distribution, where (2) "into" regions consist of $17 \%$, and (3) "away" regions consist of 50\% of directional distribution. All the immobilized protein groups had similar percentages of axons turning (45 to $47 \%$ ) within 0 to $<60^{\circ}$ and 120 to $<180^{\circ}$. Within the $1 \mathrm{X}$ bNGF immobilized region, $42 \%$ of neurites were directed straight into the region at 60 to $<120^{\circ}$, and $45 \%$ were within the turning regions. A small percentage, $13 \%$, was directed away from the $1 \mathrm{X}$ bNGF immobilized source. These percentages were similar to the coimmobilized group with $2.5 \mathrm{X}$ bNGF $+0.1 \mathrm{X}$ bSema3A, with $40 \%$ of axons directed toward the 
source, $45 \%$ turning and only $15 \%$ moving away from the source. With $1 \mathrm{X}$ bSema3A alone and $0.5 \mathrm{X} \mathrm{bNGF}+5 \mathrm{X}$ bSema3A, neurite orientation behaved similarly with a larger percentage of axons being directed away from the immobilized region, $34 \%$ and $38 \%$, respectively, compared to $20 \%$ and $17 \%$ of axons continuing into the immobilized region. $1 \mathrm{X}$ bNGF $+1 \mathrm{X}$ bSema3A had the largest turning percentage of $47 \%$, with $23 \%$ of neurites directed into the immobilized source and $30 \%$ turned away.

Table 2. Orientation of the of Neurites inside the Immobilized Protein Regions

\begin{tabular}{|c|c|c|c|c|c|c|}
\hline $\begin{array}{c}\text { Neurite Guidance } \\
\text { within } \\
\text { Immobilized } \\
\text { Regions }\end{array}$ & Control & $\begin{array}{c}1 \mathrm{X} \\
\text { bNGF }\end{array}$ & $\begin{array}{c}1 \mathrm{X} \\
\text { bSema3A }\end{array}$ & $\begin{array}{c}\text { 0.5 X } \\
\text { bNGF + } \\
5 \text { X } \\
\text { bSema3A }\end{array}$ & $\begin{array}{c}1 \mathrm{X} \\
\text { bNGF + } \\
1 \mathrm{X} \\
\text { bSema3A }\end{array}$ & $\begin{array}{c}2.5 \mathrm{X} \\
\text { bNGF + } \\
\text { 0.1 X } \\
\text { bSema3A }\end{array}$ \\
\hline $\begin{array}{c}0-<60^{\circ}, 120-<180^{\circ} \\
\text { (Turning) }\end{array}$ & $38 \%$ & $45 \%$ & $46 \%$ & $45 \%$ & $47 \%$ & $45 \%$ \\
\hline $\begin{array}{l}60-<120^{\circ} \\
\text { (Into) }\end{array}$ & $11 \%$ & $42 \%$ & $20 \%$ & $17 \%$ & $23 \%$ & $40 \%$ \\
\hline $\begin{array}{l}180-<360^{\circ} \\
\text { (Away) }\end{array}$ & $51 \%$ & $13 \%$ & $34 \%$ & $38 \%$ & $30 \%$ & $15 \%$ \\
\hline
\end{tabular}

ICC staining and analysis revealed that the tip of neurites located inside regions containing $1 \mathrm{X}$ and $5 \mathrm{X}$ bSema3A were prone to cytoskeletal disruption of actin filaments and microtubules (Fig. 6). This disruption of structure occurred at the periphery of the DRG extract (Fig. 6B-D); however, the overall DRG cell bodies and axons closer to the center of the extract showed healthy cytoskeletal structure after $5 \mathrm{~d}$ (Fig. 6E-F). It is important to note that these particular DRGs are located in the immobilized regions and the representative images were not used in guidance measurements but were stained to show how microtubule breakdown affects the periphery of the DRG. Additionally, representative phase contrast images revealed axon outgrowth, inhibition and turning as they complement the quantitative data above (Fig. 7). There was evident axon extension and a greater number of neurites into $1 \mathrm{X}$ bNGF regions and axon inhibition away from $1 \mathrm{X}$ bSema3A regions (Fig. 7A-B). Axons that were located in $1 \mathrm{X}$ bSema3A regions also exhibit axon repulsion as well as co-immobilized groups of $0.5 \mathrm{X}$ bNGF 
$+5 \mathrm{X}$ bSema3A and $1 \mathrm{X}$ bNGF $+1 \mathrm{X}$ bSema3A (Fig. 7C-E). However, at $2.5 \mathrm{X}$ bNGF, neurites were drawn into the source in the presence of low $0.1 \mathrm{X}$ bSema3A concentrations (Fig. 7F).

\section{Discussion}

Permissive and inhibitory proteins work together in the nervous system to pattern and create networks for proper motor and sensory function in the organism. Sema3A forms a molecular boundary in areas close to sensory (DRG) projections in order to inhibit branching and steer axons along their proper tracts $[12,13,25]$. Additionally, in mice it has been shown that TrkA expressing DRGs are located in close proximity to NGF synthesizing cells along these projections as well [11]. Therefore, we sought to analyze how DRGs would respond upon encounter of a step change single source of immobilized bNGF and bSema3A. Additionally, we studied how neurites responded to encountering a step change to co-immobilized regions of bNGF and bSema3A. This model can translate to nervous system injury models where axons need both a permissive and inhibitory cue to precisely steer them to their target tissue. This platform can also be implemented in injury or diseased regions where a sustained neurotrophin source is necessary to cross an inhibitory boundary.

First, concentration responses based on neurite outgrowth and number was assessed for each protein with DRG placed and grown on uniform concentrations of immobilized bNGF and bSema3A. Immobilizing bNGF at various concentrations did not have a significant effect on enhancing axon outgrowth over soluble administration (Fig. 2A, Supp. Fig. 1), but there was a noted difference seen in the number of neurites where $2.5 \mathrm{X}$ bNGF has more neurites compared to $0.5 \mathrm{X}, 5 \mathrm{X}$ and $10 \mathrm{X}$ bNGF (Fig. 2B). We have observed this result in previous studies with our always present concentration of immobilized bNGF protein in which neurite number is affected but not length [19]. Typically, NGF undergoes retrograde transport to the cell soma in 
order to initiate signaling pathways of elongation, differentiation and survival [26, 27]. However, alternative branching and elongation pathways are available when NGF binds and activate TrkA/p75NTR locally at the growth cone [28-30]. Another reason there was no noticeable difference could be that the surface area concentrations were at or above the saturation point for DRG outgrowth. It has been measured that endogenous NGF levels in DRG are in the $\mathrm{pg} / \mathrm{mg}$ wet tissue range [31-33] and serum levels have been shown to vary from about $8-10 \mathrm{ng} / \mathrm{mL}$ in mice [34]. Interestingly, super physiologic volumetric concentrations (>10 $\mathrm{ng} / \mathrm{mL})$ have been shown to initiate neurite elongation when presented in the form of gradients $[35,36]$. Thus, building on our immobilized bNGF concentration experiments by testing gradient responses is the next step and would likely potentiate neurite outgrowth in our model.

DRG responded to immobilized uniform bSema3A concentrations by significantly decreasing neurite length over the range of concentrations with minimal effect on neurite number (Fig. 2C-D). Similarly, when soluble Sema3A was added in conjunction with soluble NGF in a DRG outgrowth study, there was no significant change in the number of neurites compared to NGF alone but a significant reduction in length [37]. As previously mentioned, Sema3A is expressed throughout the peripheral nervous system [13, 25, 38]. However, specific endogenous levels have not been clearly quantified. Therefore our concentration ranges were based off previous experiments using soluble Sema3A in order to initiate growth cone inhibition $[39,40]$. Sema3A is known to initiate growth cone collapse in DRGs and cause cytoskeletal breakdown of microtubule assembly and actin largely via cofilin activation [41-44]. These morphological changes are evident in our study for both the concentration analysis and co-immobilized experiment and result in decreasing neurite length (Fig. 3F, 6). It is interesting that immobilized bSema3A concentrations are orders of magnitude smaller than bNGF groups, but they affect 
neurite length even at the smallest concentration $\left(0.01 \mathrm{ng} / \mathrm{mm}^{2}\right)$. One previous study showed that Sema3A outgrowth inhibition is more sensitive after DRGs have been exposed to NGF [39]. This result could explain the drastic decrease in length at every increasing concentration of bSema3A over $5 \mathrm{~d}$ after $24 \mathrm{~h}$ exposure to NGF (Fig. 2C) and also be an indicator to reducing neurite length in the co-immobilized groups describe further below (Fig. 4, Supp. Fig. 2).

Many axon guidance models have implemented chemotropism through NGF gradients as this is the agreed upon main physiologic mechanism [45]. Guidance studies utilizing immobilized NGF or Sema3A have shown significant guidance is better obtained with a steeper gradient, however, these gradients were immobilized in a stepwise fashion and neurites were exposed to regions containing no NGF or Sema3A source before guidance was initiated [46, 47]. Our study did not implement gradients because we first wanted to examine the response of neurites to a single concentration in close proximity to the DRG, which could translate on the cellular level into a single step of a gradient. As a result, we implemented an immobilization scheme that allowed for the proper protein-cell interaction, which is advantageous compared to just adsorbing or incorporating the molecules in the substrate [19]. The control group resulted in uniform distribution for both neurite number (Fig. 4A) and orientation (Fig. 5A), meaning the axons did not have a directional preference. DRG neurites were attracted toward the $1 \mathrm{X}$ bNGF source with a greater number of neurites inside the immobilized region (Fig. 4B, Fig. 7A) and of these neurites a smaller percentage (13\%) of them are turning back away from the region (Table 2). This attraction response is expected for a single cue of bNGF, as DRGs were able to detect the change in concentration and orient neurites towards the source. For $1 \mathrm{X}$ bSema3A, longer and more neurites were outside the immobilized region (Fig. 4C, Fig. 7B) and, of the axons inside the region, 34\% are directed away from the immobilized protein (Fig. 7C). Recently, a 
three-dimensional axon outgrowth model showed similar repulsion activity of neurites when placed near a source of a single concentration of immobilized Sema3A [48].

We also analyzed how dual immobilized cues affected DRG outgrowth and orientation in order to determine interplay of immobilized bNGF and bSema3A as others have examined their soluble interaction on DRG outgrowth and guidance [37, 39, 49]. As bNGF surface concentrations decrease from $0.86 \mathrm{ng} / \mathrm{mm}^{2}$ to $0.43 \mathrm{ng} / \mathrm{mm}^{2}(1 \mathrm{X}$ to $0.5 \mathrm{X}$ ) and bSema3A concentrations increase from $0.10 \mathrm{ng} / \mathrm{mm}^{2}$ to $0.49 \mathrm{ng} / \mathrm{mm}^{2}(1 \mathrm{X}$ to $5 \mathrm{X}$ ), there was a reduction in neurite length into the immobilized region. This phenomenon can result from the interaction between NGF p75NTR and Sema3A receptors, neuropilin-1 and plexin A4, where p75NTR partners with neuropilin-1 and plexin A4 receptors in order to attenuate axonal extension [50]. Previous work by Ben-Zvi et al. utilizing soluble NGF and Sema3A show similar results to our study where high concentrations of NGF (40 ng/mL) plus low concentrations of Sema3A (6-10 pM) will decrease outgrowth rates as it can directly dephosphorylates two main sites on TrkA, [39]. The study of cofilin activation in the presence of both NGF and Sema3A has not been reported, but these proteins alone have been shown to activate and deactivate cofilin, which is a vital protein in actin depolymerization and turnover, initiating axon attraction or repulsion, respectively [51, 52]. The classical microtubule and actin disruption inside regions containing 1 $\mathrm{X}$ and $5 \mathrm{X}$ bSema3A indicates the potency of bSema3A at inhibiting neurite extension even in the presence of immobilized bNGF (Fig. 6). We have seen this cytoskeletal disruption in our previous studies with immobilized bSema3A and soluble NGF [19].

Directional preference for neurites already inside the immobilized region were divided into three orientations: into, turning, and away. Even though there are no gradients present and there is an assumed homologous distribution of immobilized bNGF and bSema3A, there were 
non-uniform distributions for neurite orientation within the immobilized regions. The majority of the axons for all the immobilized groups were located in the "turning" or "into" regions. However, there were statistical differences seen between groups, indicating the effects immobilized bSema3A had on neurite orientation. It was observed for $1 \mathrm{X}$ and $5 \mathrm{X}$ bSema3A groups that axons were turning or directed away from the immobilized region even in the presence of $1 \mathrm{X}$ and $0.5 \mathrm{X}$ bNGF, respectively (Fig. 7C-E), their turning percentages were similar to the single immobilized $1 \mathrm{X}$ bSema3A group (Table 2), and there was no significant difference between their neurite distribution (Fig. 5). Lower immobilized bSema3A (0.1 X, 0.01 $\left.\mathrm{ng} / \mathrm{mm}^{2}\right)$ concentration with high immobilized bNGF concentration $\left(2.5 \mathrm{X}, 2.16 \mathrm{ng} / \mathrm{mm}^{2}\right)$ did not steer the distribution of axons away from the co-immobilized regions as percentages and neurite orientation were statistically similar to $1 \mathrm{X}$ bNGF (Table 2, Fig. 7F). However, there is a slight skew in the mean orientation angle $\left(73^{\circ}\right)$ for $2.5 \mathrm{X}$ bNGF $+0.1 \mathrm{X}$ bSema3A (Fig. 5F) compared to the $1 \mathrm{X}$ bNGF group $\left(86^{\circ}\right.$; Fig. 5B) indicating the lowest concentration of bSema3A examined did have a slight influence on growth cone orientation. It has been shown that the ratio of cyclic adenosine monophosphate (cAMP) and cyclic guanosine monophosphate (cGMP) determine axon turning in retinal ganglion cells, where high levels of cAMP to cGMP result in attraction and repulsion is cause by low levels of cAMP to cGMP [53]. More specifically, laminin-1 coexpressed in regions containing netrin-1, decreases cAMP levels converting axon attraction by netrin-1 into repulsion [54]. The crosstalk between these two molecules are responsible for steering retinal ganglia axons out of the retina into the optic nerve head, the beginnings of patterning the visual system. Also the modulation of these cyclic nucleotides has initiated attraction of Xenopus spinal neurons in the presence of semaphorins instead of growth cone turning and repulsion $[53,55]$. Therefore, it can be hypothesized that cGMP levels are higher in 
co-immobilized groups containing $1 \mathrm{X}$ and $5 \mathrm{X}$ bSema3A which led to greater axon turning and that the small concentration of bSema3A most likely contributed to slowing axonal growth rate but was not high enough to cause sufficient repulsion.

It is worth noting that direct comparisons of axonal responses to immobilized versus soluble protein are difficult despite some similarities observed. Much of this comes down to the fact that signaling initiation event via transmembrane receptors is similar, but the internal mechanisms may diverge, especially since activated growth factor-receptor complexes are not internalize and transported within the neuron [47]. Regardless, in this study we were able to examine single and dual immobilized cues so that we can first establish how certain concentrations elicit DRG outgrowth and turning. Knowing the sensitivity of DRGs when exposed to both bNGF and bSema3A, we can now formulate various guidance platforms that are tailored to specific injury/diseased models. Specifically understanding the role of semaphorins and other inhibitory proteins can fine tune future guidance platforms. As mentioned above, Sema3A has been utilized to inhibit axon extension into undesired regions through uniform immobilization [48]. However, Sema2A has been shown to be expressed as a gradient to axons that project into the CNS, and steeper changes in concentrations of endogenous Sema2A result in minimizing target innervation error, keeping the axon along its intended path [56]. Recently, Curley et al. implemented a guidance model with NGF and Sema6A, a transmembrane semaphorin, in which soluble bath NGF had no effect on immobilized Sema6A gradient induced DRG guidance, but when soluble NGF gradients were implemented against immobilized Sema6A gradients, DRGs overcame the chemorepulsive nature of Sema6A [57]. This is an excellent foundation for our study as the implementation of bNGF gradients would be beneficial to extend axons over long distance as well as encourage axons to cross inhibitory barriers 
(presented as gradients or uniform concentrations) encountered intrinsically after nervous system injury. Overall our study is in agreement with others, that the steepness in the change in protein concentration is vital in order to initiate or inhibit axon guidance.

\section{Conclusion}

Repulsive guidance cues such as Sema3A that result in inhibited axon outgrowth and branching while causing growth cone turning and collapse, are typically viewed as unimportant in regenerative strategies. When used alone a repulsive cue typically results in blocking neuronal regeneration after injury. Our work supports the finding of others that inhibitory biomolecules should be used in conjunction with permissive signals to help control and fine-tune axonal pathfinding, resulting in a balanced guidance system $[7,58]$. The experiment reported here is the first to co-immobilize bNGF and bSema3A in a single region at varying concentrations to demonstrate guidance (encountered step change) while analyzing DRG outgrowth, number of neurites and turning. Axons respond to immobilized bSema3A, when co-immobilized with bNGF, through axon inhibition and turning at similar or lower surface area concentrations compared to bNGF. Immobilized bNGF at its highest concentration $\left(2.16 \mathrm{ng} / \mathrm{mm}^{2}\right)$ combined with immobilized $\mathrm{bSema} 3 \mathrm{~A}$ at $0.01 \mathrm{ng} / \mathrm{mm}^{2}$ resulted in diminished axon turning, but, this minute concentration of bSema3A still reduced axon extension. The combination of both cues indicates the sensitivity and complexity of axon responsiveness to a multi-cued co-immobilized model. With this knowledge our immobilization strategy and guidance platform can be fine-tuned (through spatial patterning or temporal administration of guidance cues) for future direct application in nervous system injury models.

\section{Acknowledgements}


We would like to thank the University of Akron for supporting this research as well as Jeannette Jernigan who helped acquire data through funding provided by the National Science Foundation through the Research Experiences for Teachers program (Award Number: 1161732). 
Figure 1. Experimental set-up and analysis for DRG concentration and co-immobilization studies. Proteins were immobilized through attachment of the free sulfhydryl end of the crosslinker covalently bonding with maleimide and the streptavidin interacts with the biotinylated proteins. DRG explants were placed in 48-well-plates containing either bNGF or $\mathrm{bSema3A}$ at increasing concentrations. Additionally, DRGs were place around a $13 \mathrm{~mm}$ diameter immobilized region in a 6-well-plate containing both bNGF and bSema3A. Neurite number, length and angle measurements determined overall neurite outgrowth and guidance.

Figure 2. DRG outgrowth in response to various immobilized bNGF and bSema3A concentrations at day 5. (A-B) Neurite length and number after $5 \mathrm{~d}$ in serum free medium in the presence of immobilized bNGF. (C-D) DRG explants were exposed to soluble NGF for $24 \mathrm{~h}$ in serum free medium. Neurite length and number were measured at day 5 at various immobilized bSema3A concentrations. Mean \pm SD. Letters denote significance by ANOVA.

Figure 3. Representative phase contrast images of immobilized concentrations of bSema3A. After protein immobilization DRG extracts were seeded in serum free medium containing soluble NGF. After $24 \mathrm{~h}$ fresh medium containing no NGF was added for the remainder of the study. (A-E) Images of DRGs at each immobilized concentration at day 5. (F) Axons exposed to $1 \mathrm{X}$ bSema3A show breakdown and collapse of structural integrity as depicted by arrows. Scale bar $=100 \mu \mathrm{m}$.

Figure 4. Two-variable radial plot indicating the number and length of axons from whole DRGs. DRG neurites are either entering into the immobilized protein region $\left(0\right.$ to $\left.<180^{\circ}\right)$ or are outside the immobilized protein region $\left(180\right.$ to $\left.<360^{\circ}\right)$. (A) DRG with no immobilized protein present results in uniform distribution and the majority of length $<1000 \mu \mathrm{m}$. (B) $1 \mathrm{X}$ bNGF attracts more and longer axons inside the immobilized regions and (C) $1 \mathrm{X}$ bSema3A has more and longer axons outside the immobilized source. (D-F) Co-immobilization of bNGF and bSema3A. (D) $5 \mathrm{X}$ bSema3A concentrations with $0.5 \mathrm{X}$ bNGF cause shorter and less neurites in the immobilized region and show a strong mean vector of more axons directed completely opposite of the immobilized region. (E) There is an even distribution of neurites for $1 \mathrm{X} b N G F+1 \mathrm{X}$ bSema3A, but a higher percentage of longer axons are directed into the immobilized region. $(F)$ $2.5 \mathrm{X} \mathrm{bNGF}+0.1 \mathrm{X}$ bSema3A results in a higher number of neurites inside the immobilized region. There were 13-16 DRG extracts analyzed per group resulting in 800-1000 neurites measured for each group.

Figure 5. Neurite orientation and turning within the co-immobilized protein regions fall within three regions as depicted by the illustration. (A) The control group was uniformly distributed showing that neurite did not display a particular preference in orientation. (B) A majority of neurites are continuing into the $1 \mathrm{X}$ bNGF region. (C-E) For groups containing $1 \mathrm{X}$ and $5 \mathrm{X}$ bSema3A, a greater percentage of axons were in the turning regions or directed away from the source even with groups co-immobilized with bNGF. (F) Low concentrations of $0.1 \mathrm{X}$ bSema3A did not cause steering of axons when immobilized with $2.5 \mathrm{X}$ bNGF, resulting in a higher percentage of neurites continuing into the co-immobilized region. There were 13-16 DRG extracts analyzed per group resulting in 250-350 neurites measured for each group within the immobilized regions. 
Figure 6. ICC images showing cytoskeletal changes caused by immobilized bSema3A in conjunction with immobilized bNGF. (A) Control DRG neurites with intact microtubules (red) and actin (green). (B-D) Immobilized $1 \mathrm{X}$ and $5 \mathrm{X}$ bSema3A cause disruption of microtubule and actin assembly at the periphery of the outgrowth of the DRG extract. (E-F) Complete view of DRG extract showing healthy microtubule structures closer to the cell bodies. DRG are located inside the co-immobilized regions. $\beta$ III Tubulin $=$ Red. Green $=$ Phallodin. $(A-D)$ Scale bar $=50$ $\mu \mathrm{m}$. (E-F) Scale bar $=100 \mu \mathrm{m}$.

Figure 7. Representative phase contrast images of axon guidance. (A) Neurites are extending into regions containing $1 \mathrm{X} \mathrm{bNGF}$ and are longer than axons outside region. (B) Axon inhibition is shown as shorter neurites are located toward the immobilized $1 \mathrm{X}$ bSema3A region. (C) Neurites inside $1 \mathrm{X}$ bSema3A regions also show characteristic axon repulsion where they are turning and directed away from the protein source. (D-E) $5 \mathrm{X}$ and $1 \mathrm{X}$ bSema3A repel neurites from co-immobilized regions containing $0.5 \mathrm{X}$ and $1 \mathrm{X}$ bNGF, respectively. (F) $2.5 \mathrm{X}$ bNGF dominates $0.1 \mathrm{X}$ bSema3A signal by attracting DRG axons into the co-immobilized region. The dashed line is the immobilized region boundary with the (*) indicating the inside of the immobilized area. Arrows in (C-E) highlight neurite repulsion and turning, where arrows in (D) are indicating axon outgrowth and attraction. Scale bar $=50 \mu \mathrm{m}$.

Supplemental Figure 1. Representative phase contrast images of immobilized concentrations of bNGF at day 5. (A) Illustration depicting the experimental set-up where DRG extracts were seeded into 48 well-plates containing immobilized bNGF. (B-H) Images of DRGs at each immobilized concentration. ex $=$ DRG explant. Scale bar $=100 \mu \mathrm{m}$.

Supplemental Figure 2. Histogram of neurite lengths directed into (black) the immobilized protein region ( 0 to $<180^{\circ}$, positive percentage) or are outside (white) the immobilized protein region (180 to $<360^{\circ}$, negative percentage). (A) The control group DRG, containing no bNGF or bSema3A, were oriented randomly and had a similar distribution of neurite lengths from 0 to < $180^{\circ}$ and from 180 to $<360^{\circ}$. (B-C) $1 \mathrm{X}$ bNGF shows longer neurites directed into the immobilized region whereas $1 \mathrm{X}$ bSema3 A resulted in longer neurites outside the immobilized region. (D-F) Distribution of neurite lengths for co-immobilized groups. Number of neurites for each group are listed above and below bars on graphs. 


\section{References}

1. Houchin-Ray T, Huang A, West ER, Zelivyanskaya M, Shea LD. Spatially patterned gene expression for guided neurite extension. J Neurosci Res 2009; 87: 844-56.

2. McCormick AM, Leipzig ND. Neural regenerative strategies incorporating biomolecular axon guidance signals. Ann Biomed Eng 2012; 40: 578-97.

3. Dickson BJ. Molecular mechanisms of axon guidance. Science 2002; 298: 1959-64.

4. Pond A, Roche FK, Letourneau PC. Temporal regulation of neuropilin-1 expression and sensitivity to semaphorin 3A in NGF- and NT3-responsive chick sensory neurons. J Neurobiol 2002; 51: 43-53.

5. Skaper SD. The neurotrophin family of neurotrophic factors: An overview. Methods Mol Biol 2012; 846: 1-12.

6. Kimpinski K, Jelinski S, Mearow K. The anti-p75 antibody, MC192, and brain-derived neurotrophic factor inhibit nerve growth factor-dependent neurite growth from adult sensory neurons. Neuroscience 1999; 93: 253-63.

7. Tang XQ, Heron P, Mashburn C, Smith GM. Targeting sensory axon regeneration in adult spinal cord. J Neurosci 2007; 27: 6068-78.

8. Seeger M, Tear G, Ferres-Marco D, Goodman CS. Mutations affecting growth cone guidance in drosophila: Genes necessary for guidance toward or away from the midline. Neuron 1993; 10: 409-26.

9. Long H, Sabatier C, Ma L, Plump A, Yuan W, Ornitz DM, Tamada A, et al. Conserved roles for slit and robo proteins in midline commissural axon guidance. Neuron 2004; 42: 213-23.

10. Erskine L, Herrera E. The retinal ganglion cell axon's journey: Insights into molecular mechanisms of axon guidance. Dev Biol 2007; 308: 1-14.

11. White FA, Silos-Santiago I, Molliver DC, Nishimura M, Phillips H, Barbacid M, Snider WD. Synchronous onset of NGF and TrkA survival dependence in developing dorsal root ganglia. J Neurosci 1996; 16: 4662-72. 
12. Wright DE, White FA, Gerfen RW, Silos-Santiago I, Snider WD. The guidance molecule semaphorin III is expressed in regions of spinal cord and periphery avoided by growing sensory axons. J Comp Neurol 1995; 361: 321-33.

13. Fu SY, Sharma K, Luo Y, Raper JA, Frank E. Sema3a regulates developing sensory projections in the chicken spinal cord. J Neurobiol 2000; 45: 227-36.

14. Keizer-Gunnink I, Kortholt A, Van Haastert PJ. Chemoattractants and chemorepellents act by inducing opposite polarity in phospholipase C and PI3-kinase signaling. J Cell Biol 2007; 177: 579-85.

15. Masters KS. Covalent growth factor immobilization strategies for tissue repair and regeneration. Macromol Biosci 2011; 11: 1149-63.

16. Raman R, Sasisekharan V, Sasisekharan R. Structural insights into biological roles of protein-glycosaminoglycan interactions. Chem Biol 2005; 12: 267-77.

17. Shi M, Zhu J, Wang R, Chen X, Mi L, Walz T, Springer TA. Latent TGF-beta structure and activation. Nature 2011; 474: 343-9.

18. Sharon JL, Puleo DA. Immobilization of glycoproteins, such as VEGF, on biodegradable substrates. Acta Biomater 2008; 4: 1016-23.

19. McCormick AM, Wijekoon A, Leipzig ND. Specific immobilization of biotinylated fusion proteins NGF and Sema3A utilizing a photo-cross-linkable diazirine compound for controlling neurite extension. Bioconjug Chem 2013; 24: 1515-26.

20. McCormick AM, Jarmusik NA, Endrizzi EJ, Leipzig ND. Expression, isolation, and purification of soluble and insoluble biotinylated proteins for nerve tissue regeneration. J. Vis. Exp. 2014.

21. Bottenstein JE, Skaper SD, Varon SS, Sato GH. Selective survival of neurons from chick embryo sensory ganglionic dissociates utilizing serum-free supplemented medium. Exp Cell Res 1980; 125: 183-90.

22. Conti AM, Fischer SJ, Windebank AJ. Inhibition of axonal growth from sensory neurons by excess nerve growth factor. Ann Neurol 1997; 42: 838-46. 
23. Li GN, Hoffman-Kim D. Evaluation of neurite outgrowth anisotropy using a novel application of circular analysis. J Neurosci Methods 2008; 174: 202-14.

24. Li H, Koenig AM, Sloan P, Leipzig ND. In vivo assessment of guided neural stem cell differentiation in growth factor immobilized chitosan-based hydrogel scaffolds. Biomaterials 2014; 35: 9049-57.

25. Giger RJ, Wolfer DP, De Wit GM, Verhaagen J. Anatomy of rat semaphorin III/collapsin-1 mRNA expression and relationship to developing nerve tracts during neuroembryogenesis. J Comp Neurol 1996; 375: 378-92.

26. DiStefano PS, Friedman B, Radziejewski C, Alexander C, Boland P, Schick CM, Lindsay RM, et al. The neurotrophins BDNF, NT-3, and NGF display distinct patterns of retrograde axonal transport in peripheral and central neurons. Neuron 1992; 8: 983-93.

27. Cui B, Wu C, Chen L, Ramirez A, Bearer EL, Li WP, Mobley WC, et al. One at a time, live tracking of NGF axonal transport using quantum dots. Proc Natl Acad Sci U S A 2007; 104: 13666-71.

28. Markus A, Patel TD, Snider WD. Neurotrophic factors and axonal growth. Curr Opin Neurobiol 2002; 12: 523-31.

29. Aoki K, Nakamura T, Matsuda M. Spatio-temporal regulation of Rac1 and Cdc42 activity during nerve growth factor-induced neurite outgrowth in PC12 cells. J Biol Chem 2004; 279: 713-9.

30. Atwal JK, Massie B, Miller FD, Kaplan DR. The TrkB-shc site signals neuronal survival and local axon growth via MEK and P13-kinase. Neuron 2000; 27: 265-77.

31. Korsching S, Thoenen H. Nerve growth factor in sympathetic ganglia and corresponding target organs of the rat: Correlation with density of sympathetic innervation. Proc Natl Acad Sci U S A 1983; 80: 3513-6.

32. Davies AM, Bandtlow C, Heumann R, Korsching S, Rohrer H, Thoenen H. Timing and site of nerve growth factor synthesis in developing skin in relation to innervation and expression of the receptor. Nature 1987; 326: 353-8.

33. Oh EJ, Yoon YW, Lee SE, Hong SK. Changes in nerve growth factor levels in dorsal root ganglia and spinal nerves in a rat neuropathic pain model. Exp Brain Res 2000; 130: 93-9. 
34. Murphy RA, Saide JD, Blanchard MH, Young M. Nerve growth factor in mouse serum and saliva: Role of the submandibular gland. Proc Natl Acad Sci U S A 1977; 74: 2330-3.

35. Kapur TA, Shoichet MS. Immobilized concentration gradients of nerve growth factor guide neurite outgrowth. J Biomed Mater Res A 2004; 68: 235-43.

36. Moore K, MacSween M, Shoichet M. Immobilized concentration gradients of neurotrophic factors guide neurite outgrowth of primary neurons in macroporous scaffolds. Tissue Eng 2006; 12: 267-78.

37. Kaselis A, Treinys R, Vosyliute R, Satkauskas S. DRG axon elongation and growth cone collapse rate induced by Sema3A are differently dependent on NGF concentration. Cell Mol Neurobiol 2014; 34: 289-96.

38. Shepherd I, Luo Y, Raper JA, Chang S. The distribution of collapsin-1 mRNA in the developing chick nervous system. Dev Biol 1996; 173: 185-99.

39. Ben-Zvi A, Ben-Gigi L, Yagil Z, Lerman O, Behar O. Semaphorin3A regulates axon growth independently of growth cone repulsion via modulation of TrkA signaling. Cell Signal 2008; 20: 467-79.

40. Ben-Zvi A, Yagil Z, Hagalili Y, Klein H, Lerman O, Behar O. Semaphorin 3A and neurotrophins: A balance between apoptosis and survival signaling in embryonic DRG neurons. J Neurochem 2006; 96: 585-97.

41. Koppel AM, Feiner L, Kobayashi H, Raper JA. A 70 amino acid region within the semaphorin domain activates specific cellular response of semaphorin family members. Neuron 1997; 19: 531-7.

42. Tamariz E, Wan AC, Pek YS, Giordano M, Hernandez-Padron G, Varela-Echavarria A, Velasco I, et al. Delivery of chemotropic proteins and improvement of dopaminergic neuron outgrowth through a thixotropic hybrid nano-gel. J Mater Sci Mater Med 2011; 22: 2097-109.

43. Schmidt EF, Strittmatter SM. The CRMP family of proteins and their role in Sema3A signaling. Adv Exp Med Biol 2007; 600: 1-11.

44. Liu BP, Strittmatter SM. Semaphorin-mediated axonal guidance via Rho-related G proteins. Curr Opin Cell Biol 2001; 13: 619-26. 
45. Letourneau PC. Chemotactic response of nerve fiber elongation to nerve growth factor. Dev Biol 1978; 66: 183-96.

46. Joddar B, Guy AT, Kamiguchi H, Ito Y. Spatial gradients of chemotropic factors from immobilized patterns to guide axonal growth and regeneration. Biomaterials 2013; 34: 9593-601.

47. Yu LM, Miller FD, Shoichet MS. The use of immobilized neurotrophins to support neuron survival and guide nerve fiber growth in compartmentalized chambers. Biomaterials 2010; 31: 6987-99.

48. Horn-Ranney EL, Khoshakhlagh P, Kaiga JW, Moore MJ. Light-reactive dextran gels with immobilized guidance cues for directed neurite growth in 3D models. Biomater Sci 2014; 2: 1450-1459.

49. Dontchev VD, Letourneau PC. Nerve growth factor and semaphorin 3A signaling pathways interact in regulating sensory neuronal growth cone motility. J Neurosci 2002; 22: 6659-69.

50. Ben-Zvi A, Ben-Gigi L, Klein H, Behar O. Modulation of semaphorin3A activity by p75 neurotrophin receptor influences peripheral axon patterning. J Neurosci 2007; 27: 13000-11.

51. Marsick BM, Flynn KC, Santiago-Medina M, Bamburg JR, Letourneau PC. Activation of adf/cofilin mediates attractive growth cone turning toward nerve growth factor and netrin-1. Dev Neurobiol 2010; 70: 565-88.

52. Aizawa H, Wakatsuki S, Ishii A, Moriyama K, Sasaki Y, Ohashi K, Sekine-Aizawa Y, et al. Phosphorylation of cofilin by lim-kinase is necessary for semaphorin 3A-induced growth cone collapse. Nat Neurosci 2001; 4: 367-73.

53. Nishiyama M, Hoshino A, Tsai L, Henley JR, Goshima Y, Tessier-Lavigne M, Poo MM, et al. Cyclic AMP/GMP-dependent modulation of $\mathrm{Ca} 2+$ channels sets the polarity of nerve growth-cone turning. Nature 2003; 423: 990-5.

54. Hopker VH, Shewan D, Tessier-Lavigne M, Poo M, Holt C. Growth-cone attraction to netrin-1 is converted to repulsion by laminin-1. Nature 1999; 401: 69-73. 
55. Song H, Ming G, He Z, Lehmann M, McKerracher L, Tessier-Lavigne M, Poo M. Conversion of neuronal growth cone responses from repulsion to attraction by cyclic nucleotides. Science 1998; 281: 1515-8.

56. Isbister CM, Mackenzie PJ, To KC, O'Connor TP. Gradient steepness influences the pathfinding decisions of neuronal growth cones in vivo. J Neurosci 2003; 23: 193-202.

57. Curley JL, Catig GC, Horn-Ranney EL, Moore MJ. Sensory axon guidance with semaphorin 6 a and nerve growth factor in a biomimetic choice point model. Biofabrication 2014; 6: 035026.

58. Li GN, Liu J, Hoffman-Kim D. Multi-molecular gradients of permissive and inhibitory cues direct neurite outgrowth. Ann Biomed Eng 2008; 36: 889-904. 
Graphical Abstract

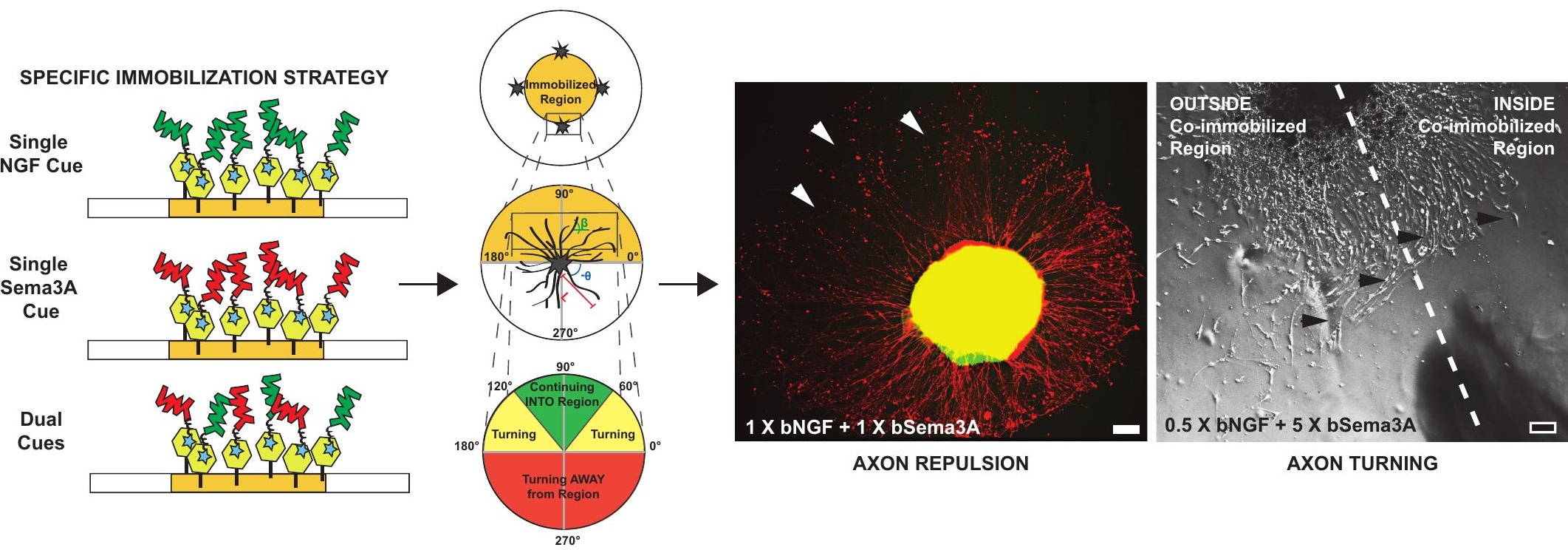




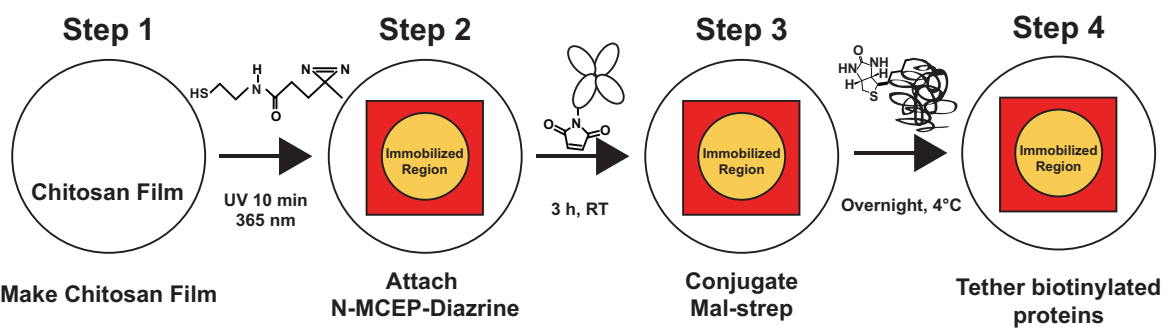

Step 5

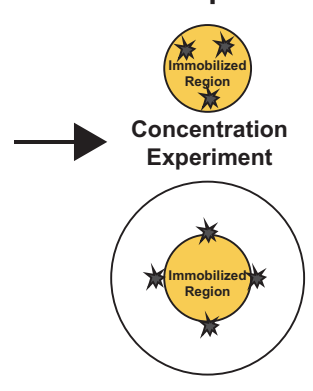

Co-immobilized Guidance Study

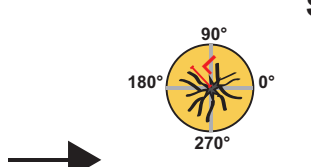

Step 6

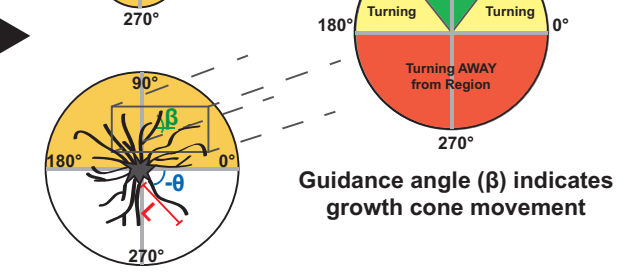

Measure neurite length (L),

number and

orientation angle $(\theta)$ 

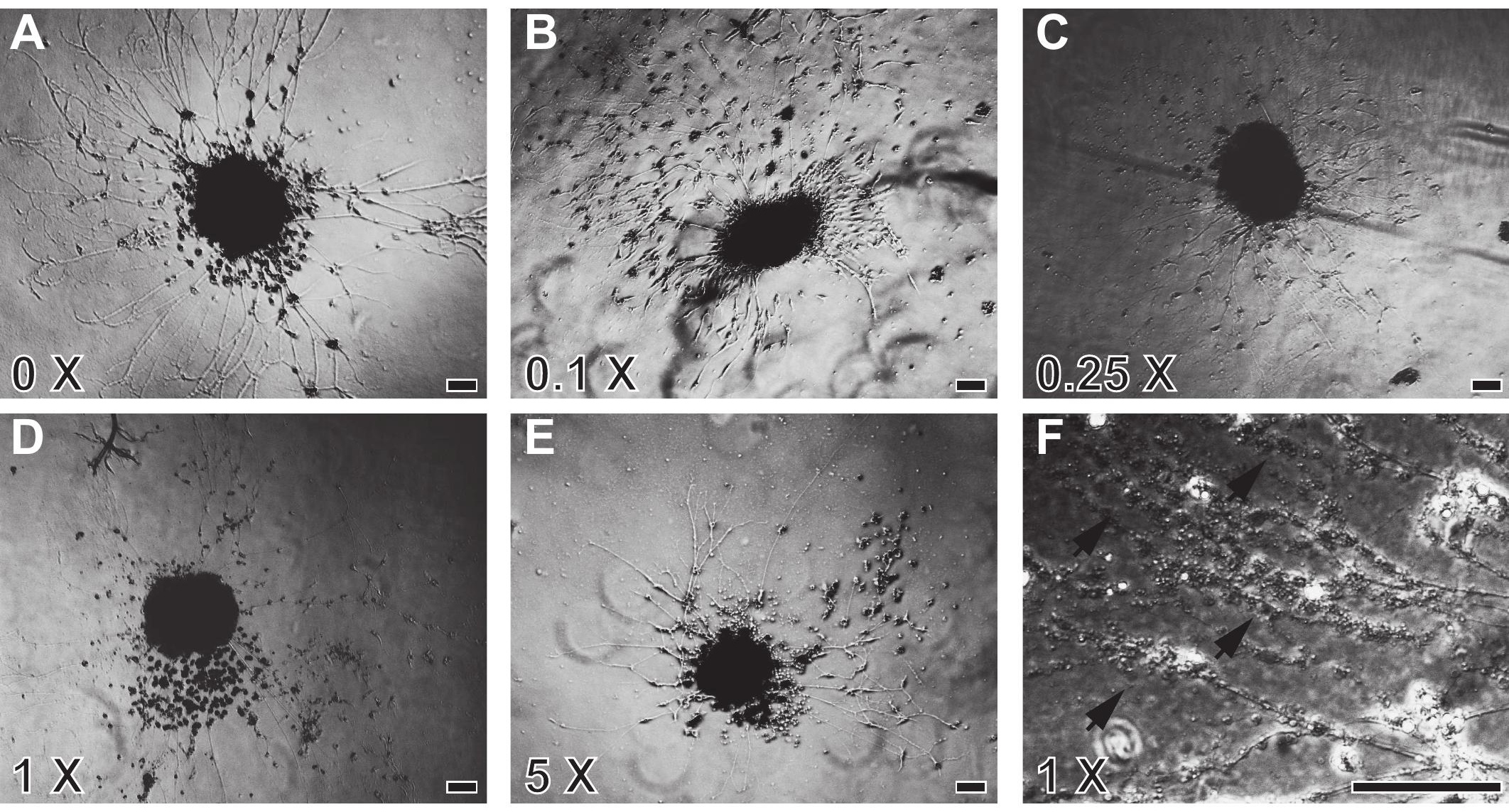
Figure 4

A

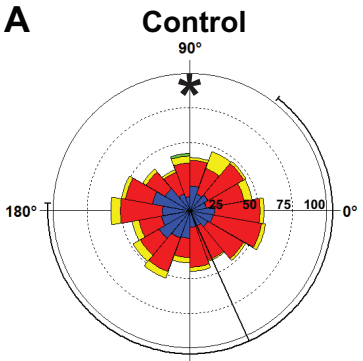

D $\quad 0.5 \times$ bNGF +

$5 \mathrm{X}$ bSema3A

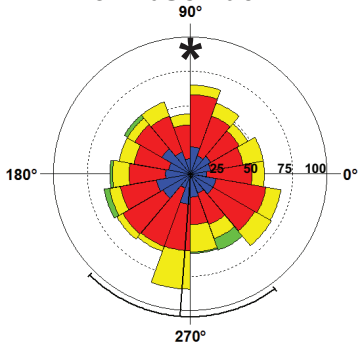

$\square 0-500 \mu \mathrm{m}$

$\square>500-1000 \mu \mathrm{m}$

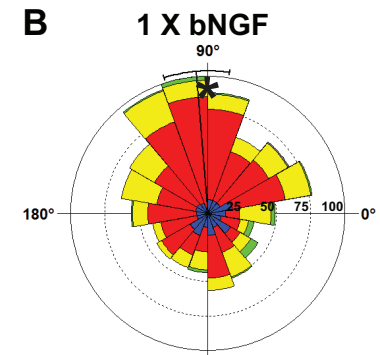

E

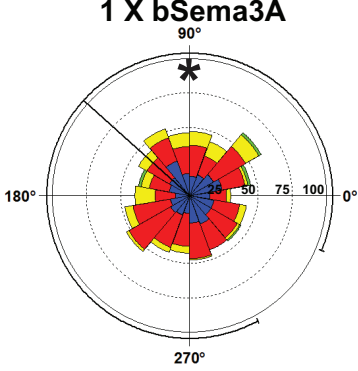

$\square>1000-1500 \mu \mathrm{m}$ $\square>1500-2000 \mu \mathrm{m}$
C $1 \mathrm{X}$ bSema3A

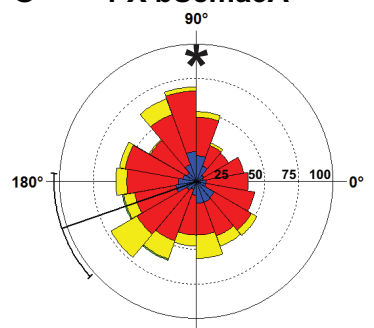

F $\quad 2.5 \mathrm{X}^{27 \mathrm{~b}^{\circ}} \mathrm{NGF}+$

$0.1 \mathrm{X}$ bSema3A

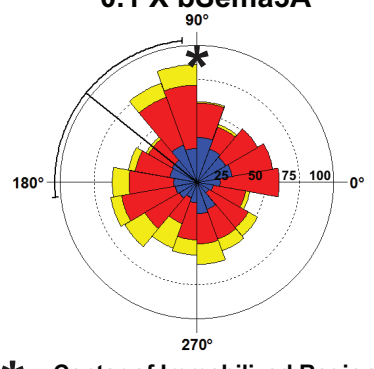

* = Center of Immobilized Region 
A

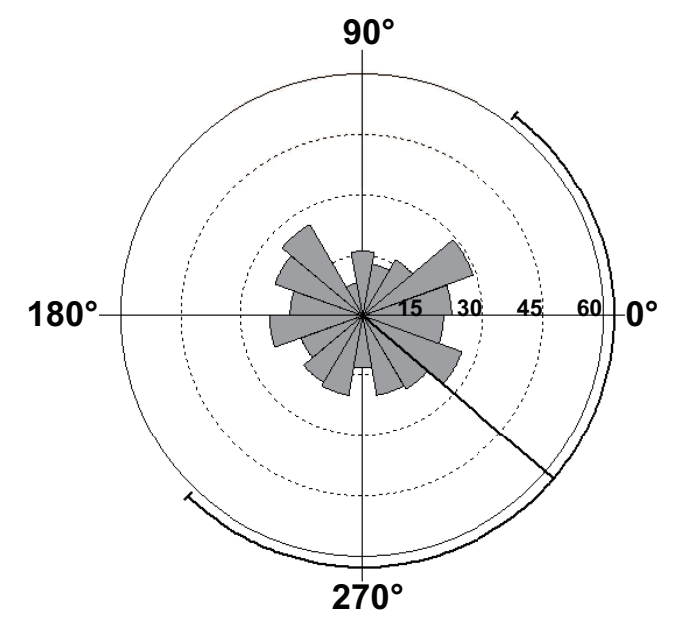

D

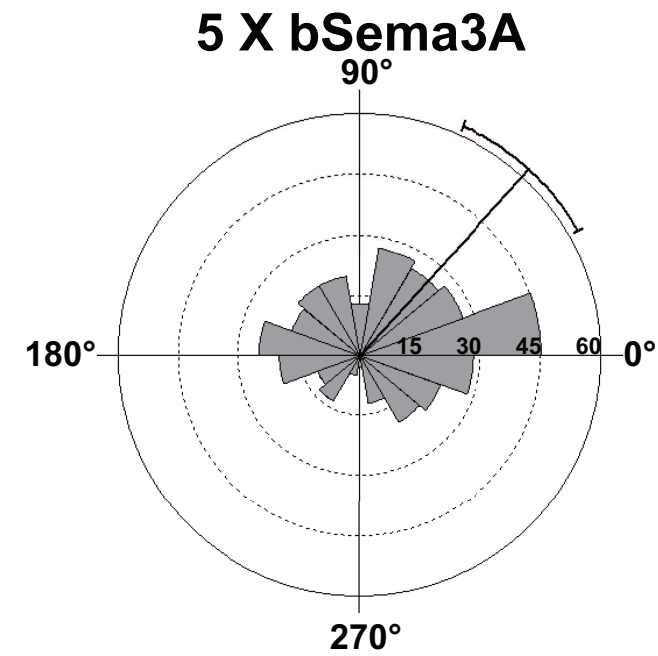

B $1 X$ bNGF

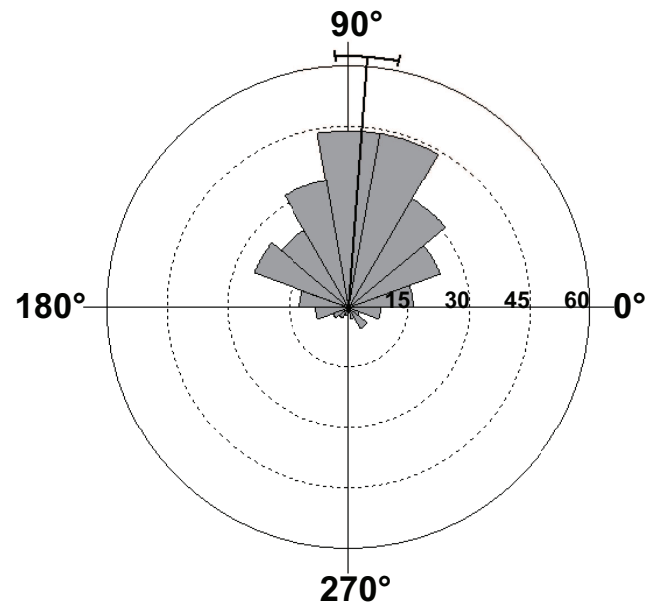

E
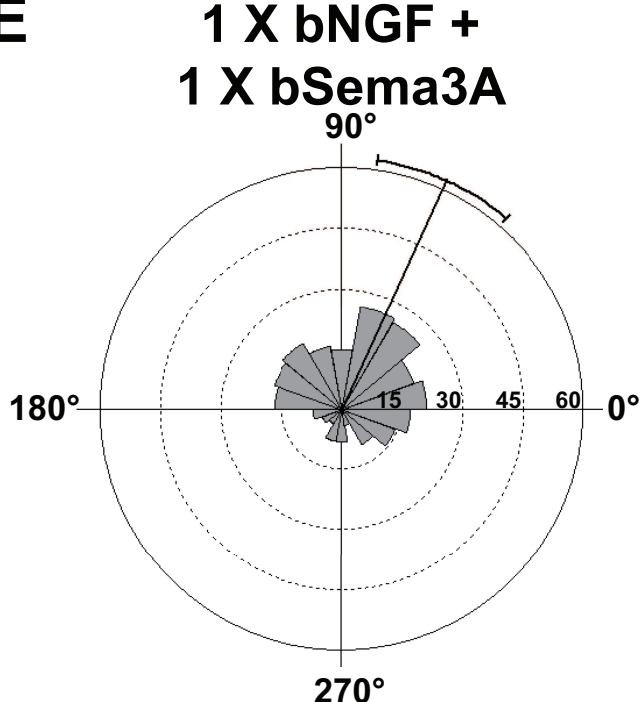

C $1 \times$ bSema3A

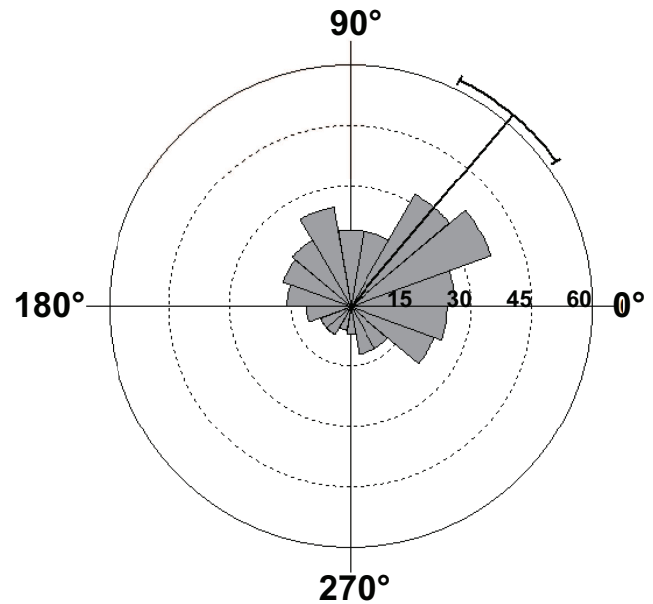

F

$2.5 \times$ bNGF +

$0.1 \times$ bSema3A

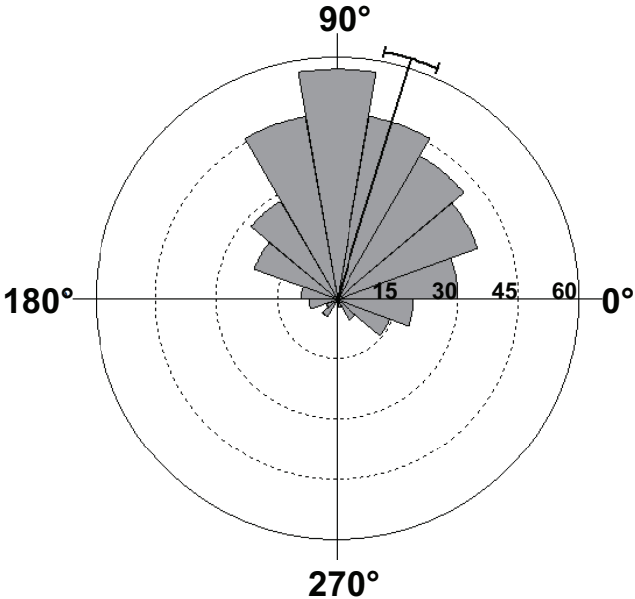

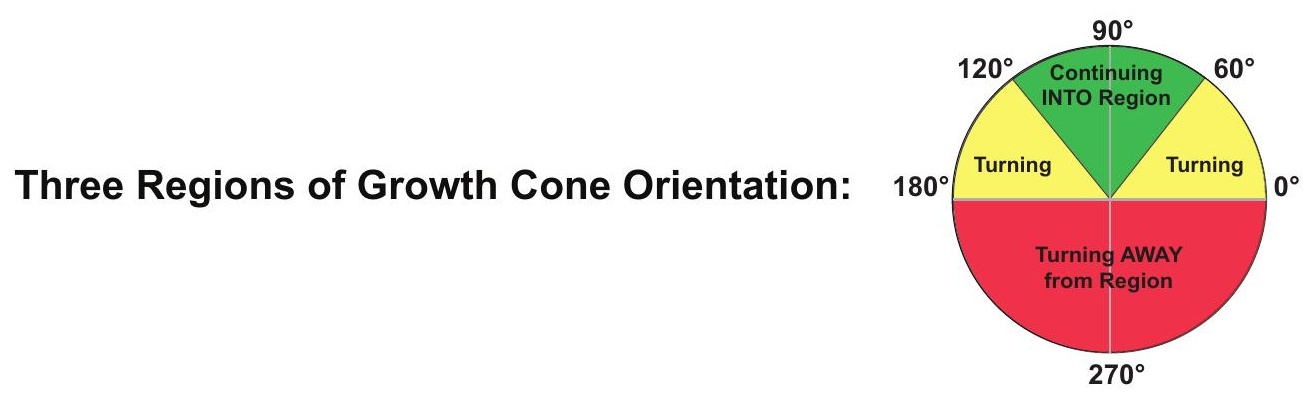




\section{A}

\section{Control}

B

$1 \mathrm{X}$ bSema3A

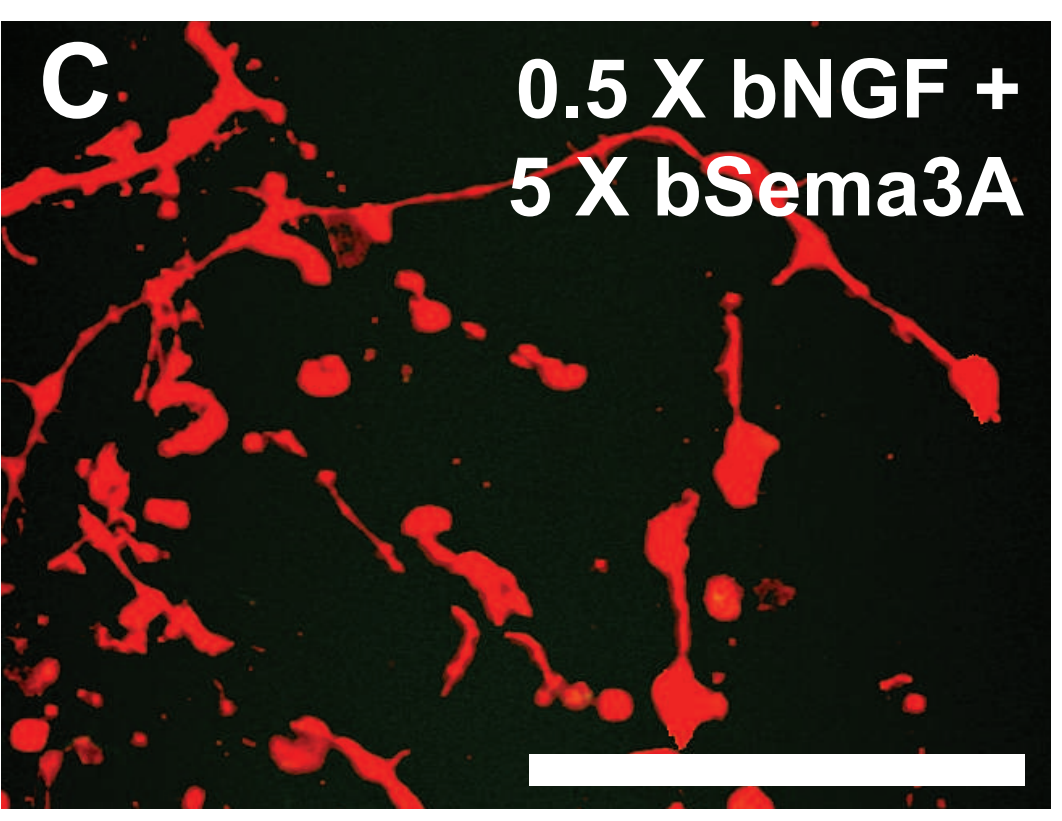

\section{E}

\section{$0.5 \times$ bNGF + $5 X$ bSema3A}

D

$1 \times$ bNGF + $1 \mathrm{X}$ bSema3A
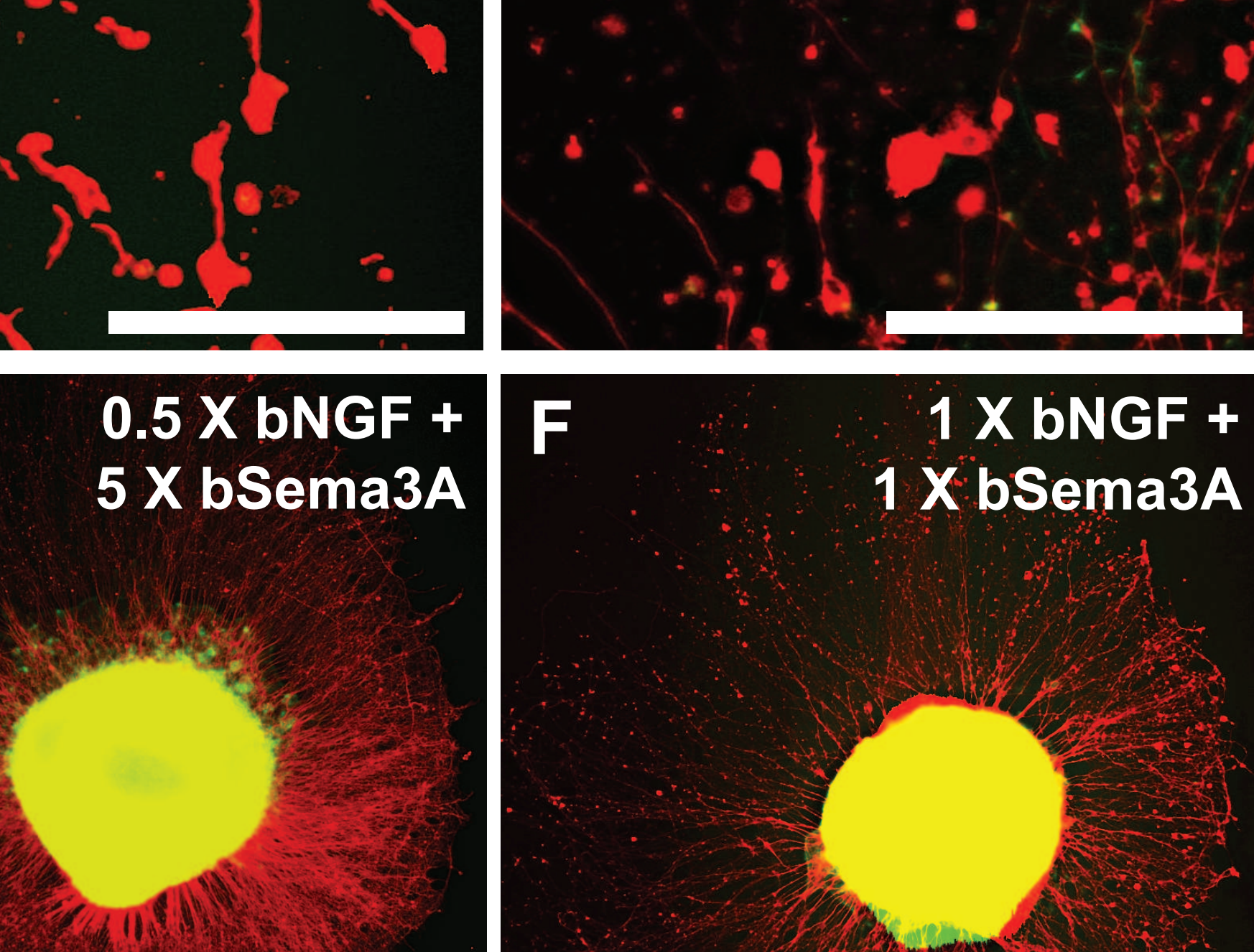
